\title{
PSICOLOGIA
}

\section{A UTOPIA DA PLENA FELICIDADE E A EXPRESSÃO DA HISTERIA DAS MASSAS NA CONTEMPORANEIDADE}

\author{
DOI: http://dx.doi.org/10.31072/rcf.v9i1.558 \\ THE UTOPIA OF HAPPINESS AND THE EXPRESSION OF HYSTERIA OF MASSES IN \\ CONTEMPORANEITY
}

Victor Hugo Coelho Rocha1; Gésica Borges Bergamini2; Evelin Samuelsson³; Cristielli Joner $^{4}$; Luiz Fernando Schneider ${ }^{5}$.

RESUMO: Fornecendo uma análise reflexiva sobre o conceito de felicidade postulado por Sigmund Freud em seu trabalho intitulado como "O Mal Estar na Civilização", obra na qual Freud desenvolveu reflexões que contemplam as exigências impostas pela civilização e a busca incansável pela felicidade, correlacionando com a dificuldade da então plenitude da existência, ou felicidade plena. Objetivos: Compreender e conceituar o conceito de felicidade e sua dinâmica na perspectiva de Freud, utilizando os percursores da obra supracitada. Métodos: Trata-se de uma análise literária com revisão bibliográfica, pois realizou-se uma leitura e busca de materiais literários que dialogassem com a perspectiva da obra e autor principal. Resultados/Discussão: o conceito de felicidade e a sua dinâmica está relacionado com os fatores psíquicos e a forma de defesa do ego, observou-se como ocorre à sublimação, mecanismo de defesa proposto por Freud, durante esse processo, e como essa dificuldade em lidar com o real pode desencadeia uma histeria coletiva, a saber, a histeria das massas, a partir da inserção do indivíduo na sociedade do espetáculo. Consideração: apesar do tempo em que a obra foi escrita pode-se olha para a sociedade atual e observar uma histeria das massas na contemporaneidade, levando em conta as características da cultura contemporânea e como os indivíduos vêm se posicionando frente a ela.

Palavras-chave: Felicidade. Psicanálise. Sublimação. Histeria na contemporaneidade. Espetáculo.

ABSTRACT: Providing a reflexive analysis on the concept of happiness postulated by Sigmund Freud in his work entitled "The Evil Being in Civilization", a work in which Freud

\footnotetext{
1 Acadêmico de Psicologia da Faculdade de Educação e Meio Ambiente - FAEMA. Autor principal desta pesquisa. Email: studiovictorocha@gmail.com. ORCID: https://orcid.org/0000-0002-4783-8359;

2 Mestra, Psicóloga e Orientadora desta pesquisa. Professora da Faculdade de Educação e Meio Ambiente FAEMA. E-mail: gpensemagro@hotmail.com. ORCID: https://orcid.org/0000-0003-0598-5366;

3 Mestra, Bióloga e Colaboradora desta pesquisa. Professora da Faculdade de Educação e Meio Ambiente FAEMA. E-mail: evelin.samuelsson@faema.edu.br. ORCID: https://orcid.org/0000-0002-0508-2709;

4 Especialista, Fisioterapeuta e Colaboradora desta pesquisa. Professora da Faculdade de Educação e Meio Ambiente - FAEMA. E-mail: cristielle.joner@faema.edu.br. ORCID: https://orcid.org/0000-0002-7476-667X;

5 Especialista, Fisioterapeuta e Colaborador desta pesquisa. Professor da Faculdade de Educação e Meio Ambiente - FAEMA. E-mail: luiz.schneider@faema.edu.br. ORCID: https://orcid.org/0000-0002-7945-2581.
} 
developed reflections that contemplate the exigencies imposed by the civilization and the relentless search for happiness, correlating with the difficulty of the then fullness of existence, or full bliss. Objectives: To understand and conceptualize the concept of happiness and its dynamics in the perspective of Freud, using the precursors of the aforementioned work. Methods: This is a literary analysis with a bibliographical revision, since a reading and search of literary materials that dialogue with the perspective of the work and main author was realized. Results / Discussion: the concept of happiness and its dynamics is related to the psychic factors and the ego defense form, it was observed as it happens to the sublimation, defense mechanism proposed by Freud, during this process, and how this difficulty in dealing with the real can unleash a collective hysteria, namely, the hysteria of the masses, from the insertion of the individual into the society of the spectacle. Consideration: despite the time the work was written one can look at present-day society and observe a hysteria of the masses in contemporary times, taking into account the characteristics of contemporary culture and how individuals are positioning themselves in front of it.

Keywords: Happiness. Psychoanalysis. Sublimation. Hysteria in contemporaneity. Spectacle

\section{INTRODUÇÃO}

Tornou-se ampla a expressão nos dias atuais da intensa necessidade do homem contemporâneo de se sentir realizado e satisfeito consigo e com seus propósitos. Denota-se que existe uma busca exacerbada por uma plena felicidade, capaz de alterar uma realidade que nem sempre resulta no alcance dos prazeres desejados: seria uma utópica felicidade capaz de alcançar essa plena satisfação no indivíduo? Observa-se uma alteração quanto ao propósito da vida e é justamente a partir disso que Freud em $\mathrm{O}$ Mal estar da Civilização tomará como ponto de partida para a investigação desse propósito com base no comportamento dos homens, os quais elencam como principal meta o alcance da felicidade (1).

Sigmund Freud destaca que esse propósito de uma utópica felicidade plena comporta dois vieses os quais são definidos de acordo com a meta almejada pelo indivíduo, sendo que a busca inalcançável pela felicidade apresentará uma meta positiva e uma meta negativa devido ao fato do indivíduo querer a ausência de dor e desprazer e vivenciar intensos momentos de prazer. Logo, tornase necessário saber que aquilo que se considera como um estado de felicidade trata-se da satisfação das necessidades elencadas por cada sujeito como portadoras de prazer. Diante disto, a felicidade descrita por Freud implica no que ele postulou em seus estudos sobre a primeira tópica quando fala sobre o princípio de prazer e desprazer (1).

Zimerman (2) menciona que a partir dos estudos de Freud, sobre o aparelho psíquico, Freud compreendeu que prazer e desprazer caminham juntos, quanto maior 
o nível de prazer no interior do aparelho mais desprazer é gerado nesse indivíduo. Logo, essa satisfação mágica e ilusória que o sujeito busca sempre acabará sendo frustrante e decepcionante porque ela não suporta as exigências e necessidades da realidade. De forma tênue, Inada (1) destaca que se trata da busca pelo sujeito de evitar o sofrimento tendo como objetivo alcançar a felicidade, e tal busca inicia-se desde o início da vida. Freud refere-se ao homem como um "infatigável caçador de prazer", sendo que lhe custa muito ter que renunciar a um prazer já sentido em prol de outros objetivos ${ }^{(3)}$.

O objetivo do estudo consiste em investigar como ocorre o processo de busca pela felicidade e a sua correlação2 com a dificuldade de alcance da tão desejava felicidade plena. Neste trabalho de revisão bibliográfica pretende-se compreender esse conceito de felicidade $e$ a sua dinâmica. Além do mais, observaremos como ocorre a sublimação, mecanismo de defesa proposto por Freud, durante esse processo, e como essa dificuldade em lidar com o real pode desencadear uma histeria coletiva, a saber, a histeria das massas, a partir da inserção do indivíduo na sociedade do espetáculo.

\section{MÉTODOS}

Para elaboração deste estudo foi realizado levantamento de conteúdo através de pesquisa bibliográfica em bibliotecas virtuais, a partir das seguintes bases de dados: BVS - Saúde, Sciello, Pepsic, Lilacs, Reme, Bireme, Capes e Google Acadêmico.

Foram incluídos estudos redigidos em língua portuguesa no tema proposto publicados dentre os anos de 2005 a 2016, extraídos de revistas científicas, além de trabalhos de conclusão de curso, dissertações de mestrado e teses de doutorado. O critério de exclusão se dirigiu a materiais não relacionados aos critérios estabelecidos para a realização desta pesquisa.

\section{FUNDAMENTAÇÃO TEÓRICA:}

\subsection{Felicidade - de uma perspectiva histórica à contemporaneidade}

A busca pela felicidade no decorrer da história levou os seres humanos a percorrer uma vida em busca de um grande e comum objetivo, sendo este, a felicidade. Em todas as épocas vividas a meta final a ser alcançada sempre foi 0 desejo de uma vida melhor. Aristóteles (384 a 322 a.C.) baseava sua crença justamente nisso, ele acreditava que o objetivo de todo homem era a felicidade $\mathrm{e}$ a mesma só seria alcançada por ele se este tivesse uma vida repleta de virtudes e características positivas que o levassem a 
merecer tal felicidade. Epicuro (341 a 270 a.C.) acreditava e menciona em uma de suas cartas sobre o respectivo tema, a felicidade, que o indivíduo somente pode alcançar a uma existência feliz a partir do momento que este abrir mão de todos excessos, de tudo que pode levar a sofrimento, como por exemplo, os demasiados compromissos sociais e medos que tornam-se empecilho para a famigerada felicidade, que se consegue levar o indivíduo a uma existência feliz. Sêneca (2 a.C. a 65 a.C.) partia do princípio que para encontrar a felicidade 0 sujeito deve se recusar a seguir a multidão, isto é, tomar consciência e entender de fato quem ele é, somente assim, conseguirá encontrar a felicidade ${ }^{(4)}$.

Russel (apud Graziano)(4) fala a respeito da necessidade social do homem de fazer parte do meio social, desta forma, ser inserido na sociedade tendo como objetivo a busca não somente da sua própria felicidade mas também da felicidade do outro, mediante isto, a visibilidade da conceituação de felicidade transcende a noção de dádiva divina e passar a ser vista como algo valioso que deve ser conquistado perante a promoção da felicidade ao outro.

Sobre tal ideia de felicidade Viktor Frankl nos elucida que a felicidade não deve-se ser considerado algo a ser buscado pois ela simplesmente vem. A felicidade é um sentido, se o ser humano a busca é falsa. Observa-se que a felicidade baseia-se sobre dois tipos de premissas, no que refere-se a premissas de natureza extrínseca nota-se que a característica que se destaca é que o sujeito passa a buscar a felicidade para muito além de si mesmo, acreditando que poderá encontra-la na aquisição de um carro novo, uma casa nova, um aparelho eletrônico que esteja em alta no mercado e os demais tipos de conquistas de caráter externo.

De outro lado, referindo-se a premissas de natureza intrínseca o sujeito busca em si mesmo a felicidade, este tem como fonte sua própria existência, acreditando que tal felicidade somente será encontrada se este trabalhar seu interior, a si, transcender a tudo que está externo a ele. Temos uma ideia de felicidade que é citada por Pascal e se correlaciona com o que é decorrente dos dias de hoje, principalmente a aqueles indivíduos que apresentam ideação suicida. Usando tal exemplo, sabe-se que muitos são os julgamentos sobre estes, entretanto, de acordo com o pensamento de Pascal, até mesmo o sujeito que busca a morte, tendo por diversos métodos encontra-la, na verdade, tem como único objetivo ser feliz, a sua vontade de encontrar uma felicidade que já não existe 
no interior de si. Buscar a morte passa a ser uma forma desse sujeito de fugir da tão apavorante e sofrida infelicidade ${ }^{(5)}$.

A sociedade contemporânea encontra-se a todo o momento buscando formas de alcançar a felicidade pelo prazer, deste modo, tenta-se evitar todo e qualquer tipo de contato com o sofrimento. Entretanto, permitir uma busca desenfreada e um alcance da suposta evitação do sofrimento seria muito perigoso para a estrutura da personalidade do indivíduo, pois se torna necessário a introdução do princípio de realidade. Segundo Saroldi (6) há uma dificuldade na atualidade em pensar coletivamente $\mathrm{e}$ essa busca por prazer de forma exacerbada introduz o homem no mundo da barbárie, distanciando-o da cultura. Para a autora, a renúncia - que nos conduziria aos processos civilizatórios - é algo que tem sido expurgado do imaginário comum. Llosa destaca que a sociedade atual tem valorizado o prazer, a fuga ao tédio, a leveza (7).

O grande precursor da psicanálise, Sigmund Freud, ao falar sobre a primeira tópica do aparelho psíquico, fazendo referência a prazer e desprazer, chegou à conclusão que não existe a possibilidade de encontrar prazer sem também experimentar o desprazer, torna-se uma meta utópica, Freud dizia que quanto maior o nível de prazer no interior do aparelho psíquico humano maior também era o desprazer que este experimentava e que precisava ser descarregado por algum meio, pelo fato de vivermos em sociedade, uma das formas utilizadas é através de exercícios, de motricidade, e é justamente por esse motivo que se pauta tal impossibilidade de satisfação irrestrita, pois o fato de vivermos em sociedade nos priva em demasiadas formas de viver nossos mais íngremes desejos ${ }^{(9)}$.

Suzuki (apud Sebold) ${ }^{(8)}$ fala sobre o "distanciamento dos afetos", no qual o homem encontra-se distante da experiência de felicidade, da alegria e de sentimentos que o levam a tal estado que ele elenca como meta, um estado feliz. Diante da dificuldade do alcance de tal felicidade utópica e das constantes cobranças da sociedade, tal individuo chega a vivenciar estados depressivos, que influência na maneira como este se relaciona com o outro e em como vive no mundo e nos rumos que está dando ao seu destino, isto devido ao ideal social que já preexiste ao seu próprio nascimento, pois mesmo antes de nascer, aqueles que se dedicarão ao próprio nascimento e cuidado já predeterminam os destinos e tornam as escolhas limitadas, logo, cada indivíduo passa a ser construídos por ideais e expectativas que não é de si 
próprio, mas sim inicialmente de seus pais e mais tarde da sociedade de acordo com os critérios de certo e errado perante a civilização.

Diante desse processo observa-se que na atualidade em decorrência da tecnologia e da necessidade do "aquiagora", a sociedade passou a cultivar uma rotina demarcada por horários de durabilidade e prazos de validade, onde 0 tempo é o senhor do seu destino, uma caminhada constante em direção a lugar nenhum, resultando como consequência deste processo o enfraquecimento do laço social, das amizades e até mesmo dos relacionamentos familiares.

Defronte a dificuldade do alcance da felicidade plena, surge um estado de infelicidade considerada por Freud como de mais fácil alcance. Inada (1) acredita que existe fontes que proveem a infelicidade no interior do indivíduo, sendo os relacionamentos humanos podendo ser muitas vezes muito inconstante e superficial, o próprio mundo exterior que refere-se também a sociedade com seus pré julgamentos e determinações e o próprio corpo, demarcado pela insatisfação do sujeito com si mesmo, buscando sempre a perfeição. Segundo Suzuki (apud Sebold) (8) o que se impregnou no interior do sujeito da contemporaneidade é que se tem muito mais valor socialmente ter algo, e apresentar algo, do que ser, e dentre ser, ser verdadeiramente feliz.

Inicialmente, o indivíduo é um ser meramente biológico que busca satisfação das necessidades ligadas somente à sobrevivência, mais tarde, conforme é inserido em seus interior os princípios sociais, tais como, o que é errado e o que é correto, o homem passa a se tornar cada vez mais insatisfeito com o que tem e com o que é, buscando cada vez mais por desejos e necessidades que excedem a verdadeira necessidade, desta forma, no impossível alcance de tais desejos, o ser humano passa a ser reprimido, tendo seus desejos postergados ou desviados de sua finalidade original (1).

Desta forma, de acordo com o jargão social para ser reconhecido como alguém no meio da sociedade não basta "ser" é necessário "ter", sendo um bom emprego, casa própria, uma família, a possibilidade de consumir produtos de boa qualidade e recém-lançados pelo mercado, objetivos elencados inconscientemente como necessários para o alcance da felicidade, a qual, forjada pelo capitalismo, aparece vinculada a possibilidade de consumo. Desta forma, de acordo com o jargão social, para "ser alguém na vida" é preciso ter uma profissão, um bom emprego, casa própria, uma família, a possibilidade de consumir produtos de boa qualidade $\mathrm{e}$ 
recém-lançados pelo mercado, objetivos que acabam sendo elencados de forma inconscientemente levando o indivíduo acreditar que somente encontrará a felicidade se aderir ao sistema capitalista que aparece vinculada a possibilidade de consumo. Observa-se que foi dada a felicidade um caráter de dever, aparecendo atrelada também ao status social e a imagem e supervalorização do corpo ${ }^{(8)}$.

De acordo com a ideologia da modernidade sentimentos negativos não podiam ser mencionados e muito menos sentidos, era proibido fazer menção de termos que fizesse conotação com sofrimento. Contudo, Bruckner destaca que o que deve desaparecer do discurso do sujeito não é o fator de sentir dor e sofrer, mas sim o fato de expressar por vias publicas tais sofrimentos, desta forma, é exigido ao suma espécie de necessidade de simulação da felicidade Bruckner (apud Sebold) ${ }^{(8)}$, desta forma o indivíduo passa a reproduzir papéis, vivendo em simulacro.

\subsection{Vivência em simulacro}

Viver em simulacro é uma realidade que culmina e ganha aplausos da maioria na sociedade contemporânea. Nesse tipo de vivência 0 indivíduo apresenta externamente uma realidade que não the pertence, camuflando a sua subjetividade e identidade tendo como motivação extrínseca a satisfação em ser aprovado pela sociedade e como motivação intrínseca o suposto alcance da felicidade plena. Nesse tipo de vivência, o indivíduo esconde a verdade, ocultando o que de fato existe, fingindo ter um padrão de vida que não tem. A simulação põe em questão a diferença do verdadeiro e do falso, do real e do imaginário, assim, os simuladores perdem o seu significado, dando lugar ao imaginário representativo, confundindo desta forma o real com a fantasia ${ }^{(9)}$.

Frederico (10) postula a respeito do mundo fantasmagórico do simulacro, ele destaca que a felicidade pode ser produzida de diversas formas, experiências, estados, ela pode ser identificada na forma de amor, de prazer sexual, de saúde, segurança, alegria, e contraponto a tais estados, aparece aqueles que causam o que causa pavor a quem busca a famigerada felicidade, desta forma, sentimentos tais como tristeza, angústia, nojo, medo e ansiedade acabam por diminuir a felicidade de cada indivíduo.

Ferraz (11) diz que o ser humano somente alcançará a felicidade quando este encontrar uma maneira coerente de viver, logo, a coerência deve demarcar a vida de tal sujeito englobando todos os aspectos, sendo materiais ou até mesmo espirituais, além do mais, o autor 
considera que a "felicidade" é a expressão que traduz a compreensão coerente $\mathrm{e}$ lúcida do mundo; ou seja, a felicidade autêntica requer uma maneira coerente de viver. Quando o sujeito abre mão da coerência em sua existência, ele abre mão de si próprio, da verdade sobre si, e passa a viver em simulacro.

Debord, prevendo esse futuro postulou que:

Essa inversão das relações entre realidade e imagem, já nos advertia que o simulacro não se tornou o mundo real, mas é o mundo real dilacerado que passou a se apresentar sob a forma de espetáculo, unificando falsamente a nossa percepção e impondo o "monopólio das aparências ${ }^{(10)}$.

Ser plenamente feliz em uma sociedade que obriga, a todo o momento, mediar desejos tornou-se um objetivo inacessível. Logo, existir na contemporaneidade trata-se muito mais de contracenar papéis do que viver de fato quem se é, creditado isto a sociedade que determina o que é socialmente aceitável, sendo que tudo que transcender a isso se torna promíscuo e patológico. Deste modo, alcançar a felicidade é uma ilusão de caráter social, organizada e desempenhada pela própria sociedade, como se refere Fontenelle ${ }^{(12)}$, pois a linha entre o aceitável e o profano é muito tênue.

Assim, o indivíduo encontra-se obrigado a todo o momento sublimar seus desejos por outros mais socialmente aceitos, mas que o impede de alcançar a tão desejada meta da felicidade. Este sujeito vive, então, através de um mecanismo egóico representado por uma sociedade também egóica.

O Ego não é algo que tem sua existência do nada, ele é construído no decorrer da existência do sujeito, assim como o ld e o Superego, o Ego também tem sua função, sendo esta a de mediar as pulsões do ld que grita pelo prazer e as exigências do superego que atua ao lado das exigências sociais, que realmente leva o indivíduo a realidade socialmente imposta. Desta forma, entende-se que é a personalidade que desenvolve os mecanismos de defesa necessário do Ego, tendo entre os principais mecanismos de defesa do Ego existentes se encontra o mecanismo de negação que consiste simplesmente na recusa do sujeito em consentir com situações que levam ao sofrimento, que causa angustia nesse sujeito (13).

Analisando esse conceito de felicidade tendo como foco o papel da cultura e na civilização na formação dos aspectos que constitui um estado de 
felicidade no sujeito, Sigmund Freud percebe que viver socialmente é ser atingido de sofrimento e repressão o tempo todo, principalmente relacionado a aquilo que desperta desejo, desta forma, surge 0 mecanismo de defesa da sublimação, por meio da sublimação, causa-se aos homens um mal-estar, porém esses sacrifícios são necessários para a existência da sociedade, desta forma o que ocorre é que com o princípio da realidade o desprazer passar a ser obrigatoriamente tolerado devido às exigências da sociedade, e assim 0 indivíduo tem que postergar sua satisfação tornando-se vulnerável a diversas fontes de sofrimento. Assim, para manter a vida, o objetivo de alcançar a felicidade plena é relegado a segundo plano. O indivíduo, mediante a sociedade, busca pela sua proteção com o objetivo de sobrevivência, pautando na segurança que uma vida social pode oferecer a ele, desta forma, esse sujeito sublima e abre mão de si, abre mão de seus desejos e troca sua felicidade por segurança, como postula Sigmund Freud (1) troca a qual pode dar origem a uma histeria de massas.

\subsection{A expressão da histeria de massas na contemporaneidade}

Almeida (14) postula que a histeria no decorrer da história pôde ser vista de diferentes formas e ângulos, como aberração pôde ser diversas formas de repreensão e tratamento, por exemplo. Até que surge Sigmund Freud e Breuer que a partir de seus estudos constataram que na verdade tratava-se de algo de origem psíquica, desta forma, baseando-se em dados científicos que eram de fato comprovados, desenvolveram um tratamento mais racional. Mediante isto, percebe-se que antes a histeria não era vista como uma questão de ordem psicológica mas sim de ordem religiosa ou até mesmo orgânica.

Ávila \& Terra ${ }^{(15)}$ conta que a histeria chegou a ser vista como uma síndrome da cultura, tendo como fator desencadeante a repressão sexual da era vitoriana. Além do mais, muitos autores, como o próprio Sigmund Freud percebiam que antes do século $X X$ a forma que os indivíduos, especialmente as mulheres, encontraram para expressar seus conflitos de ordem emocional era por meio de sintomas fisiológicos. Na era vitoriana as mulheres eram vistas como seres humanos para procriação, logo, elas não possuíam voz, não tinha força, desta forma, devido à falta de oportunidade de expressão seus corpos eram acometidos. Extirpavam das mulheres o direito a externalizar o que sentiam, entretanto, isso não fazia que as questões sexuais e carências também fossem tiradas, a única coisa que 
promovia era 0 recalcamento que desencadeava o surgimento dos sintomas conversivos.

Diante do exposto, percebe-se que inicialmente a histeria conversiva era algo que acometia mais mulheres, com 0 decorrer das décadas, passou a ser observado que poderia acometer qualquer individuo, pois a repressão e o recalque era uma alternativa de saída daquilo que não era aceito socialmente ${ }^{(16)}$. Tornou-se tão comum que não é um mal que atinge somente um pequeno grupo de pessoas, hoje, trata-se de uma espécie de histeria coletiva, a qual está sendo expressa e manifesta de maneira coletiva, como uma epidemia, onde responsabilidades, identidades e sentimentos passam a ser revogados e adquiridos de forma coletiva pelos indivíduos, como postula Melman (apud Costa \& Lang) ${ }^{(16)}$.

Ao se deparar com a impossibilidade da realização da plena e fugaz felicidade, questiona-se, onde 0 indivíduo tem investido sua libido? $\mathrm{Na}$ família, na profissão, nos filhos, no corpo, no parceiro? São muitas as questões que se colocam frente ao enigma dos desejos do indivíduo. Rocha (17) menciona que com a globalização há uma excessiva preocupação com a beleza e com o corpo, o corpo é colocado em evidência e a mídia é o principal meio difusor de modelos a serem seguidos pelos histéricos, desta forma a completude de sua existência é representada pelo corpo, corpo este que é motivo de insatisfação, de infelicidade. Inconscientemente, o sujeito histérico faz de tudo para manter seu desejo insatisfeito, desde a escolha de um objeto que quer comprar até a escolha de um parceiro amoroso, podendo dar origem a um relacionamento patológico $e$ dependente, pois visará sempre à busca por essa satisfação, pelo objetivo maior e utópico, a felicidade.

Costa e Lang (16) mencionam que atualmente a histeria pode se manifestar de duas formas, a primeira sendo através do espetáculo, e a última através de uma espécie de "comunitarismo". No fim, ambas são as formas de um sujeito se fazer notado, reconhecido. $\mathrm{E}$ atrelado à estimulação ao espetáculo podemos identificar no indivíduo histérico da contemporaneidade características do transtorno histriônico.

O DSM-IV caracteriza O TPH Transtorno de Personalidade Histriônica referindo-se a ele como uma emocionalidade encontrada no indivíduo de forma exagerada, esse indivíduo passa a desempenhar comportamentos a fim de alcançar atenção de outras pessoas, assim tendo comportamentos totalmente inadequados. Desta forma, constitui-se os 
tradicionais espetáculos ${ }^{(18)}$. Costa e Lang (16) destacam que o espetáculo surge com a necessidade de exibição, de ser visto.

\subsection{Sociedade do espetáculo e o sequestro da subjetividade}

Atualmente, nossa sociedade tem vivido naquilo que podemos intitular como a "era do espetáculo". Onde indivíduos se sujeitam a todo tipo de comportamentos e identidades para conseguir visibilidade e atenção, sociedade do espetáculo.

Tal conceito, sociedade do espetáculo, inicialmente se desenvolveu por Guy Debord, um teórico Francês, sua criação foi com a finalidade de descrever uma sociedade midiática e consumista, que se movimenta em torno do consumo de mercadorias e da própria imagem e em torno da produção, o que acabou-se por tornar valores na sociedade contemporânea ${ }^{(19)}$.

Frederico (10) postula que para Debord, o espetáculo se faz notório quando se é vendida uma imagem de indivíduo totalmente feliz, através da imagem, da mídia, da tecnologia, sendo que o primeiro a comprar tal imagem como verdade é o próprio indivíduo que está contracenando, o qual se expropria do seu verdadeiro estado. Esses indivíduos necessitam dessa visibilidade para se sentirem aceitos, reconhecidos socialmente e somente conseguirão tal visibilidade através do seu espetáculo. Como Lacan postulou ao falar do estádio do espelho, a imagem tornou-se uma das formas mais primitivas de identificação do sujeito, uma sociedade depende do olhar do outro passou a ser vista, pois tal necessidade é justamente uma forma de lutar contra sua falsa felicidade que ele por si só a vende como verdadeira.

O conceito do estádio do espelho foi desenvolvido a partir da experiência de Henry Wallon, que descreveu o modo como a criança, aos poucos, diferencia seu corpo da imagem que observa no espelho, o estádio do espelho é um momento estrutural do ser humano onde ele se reconhece na imagem de um outro no espelho. Durante esse estádio pode-se dizer que a experiência da criança a levará a uma conquista progressiva da imagem, quando a criança nasce ela estabelece uma relação de dependência com a pessoa que cuida dela, geralmente sendo a mãe aquela que irá exercer essa função, a qual suprirá todas as carências da criança tanto no plano biológico quanto no plano imaginário.

$O$ ato de satisfazer as necessidades físicas da criança é feito pela mãe segundo um código simbólico que determina esse relação entre demanda e desejo, deste modo, a mãe ocupa a função de Outro provendo a criança de alimentos, 
amor e palavras, e através dessa mediação ocorrerá o acesso ao campo do simbólico. Mediante isto, a partir desta imagem de um outro a criança se identificará com o que vê, passando a ter um referencial de si mesma e originando a constituição de um eu imaginário. O modo como 0 sujeito irá se posicionar estruturalmente em relação à realidade depende de sua articulação com os registros do imaginário e do real. Entretanto, Pereira \& Ornelas (apud Pacheco) (20) isso apenas será possível com a mediação do simbólico, que se faz presente no sujeito pela palavra.

Observa-se uma sociedade que se tornou dependente do espetáculo como uma forma de confirmação de si, de sua existência em meio a própria sociedade fugaz, a qual direcionamos a falsa realização quanto à felicidade ${ }^{(21)}$.

Entretanto, essa necessidade do olhar do outro e de sua aprovação sobre uma falsa felicidade idealizada pelo indivíduo para dar sentido a sua vida, a qual mediante o processo civilizatório é por diversas vezes reprimidas e sublimadas ocasiona por vezes o furto da individualidade deste indivíduo, que passa a pertencer à sociedade dos "indivíduos desacostumados à subjetividade" formulada por Kehl (21) que fala sobre o papel da que da indústria cultural nesse processo que não é dirigir-se ao indivíduo como um sujeito que pensa por si próprio sem a influência exacerbada da sociedade, mas sim extirpar desse sujeito sua subjetivação, sua capacidade de pensar e acima de tudo, de sentir e existir.

A subjetividade pode ser influenciada por fatores biopsicossociais, sendo determinada a partir das experiências individuais ou coletivas. Existe três aspectos da subjetividade determinados socialmente sendo que o primeiro referese ao singular - que é impar, pessoal e que não pode ser transferido a outra pessoa, diferenciando este mesmo indivíduo de outra pessoa. O segundo é o universal - que, contrariamente, pode ser compartilhado com os demais, como a linguagem e as necessidades básicas, por exemplo. Por fim, o último é o particular o qual é distinto e ao mesmo tempo pode ser compartilhado com as outras pessoas, e é justamente neste que se encontra a subjetividade contemporânea, o qual é caracterizado pela imposição de padrões propostos pela cultura vigente ${ }^{(9)}$.

Bauman (apud Ferreira) ${ }^{(9)}$ compara a subjetividade com 0 fetichismo da mercadoria propagado pelo anseio por uma felicidade instantânea e perpétua, assim quanto mais o indivíduo, convocado a responder como um personagem fictício da sua própria vida perde o norte de suas 
produções subjetivas singulares, devido a perca da sua individualidade sobre seus comportamentos mais a sociedade irá lhe devolver uma

subjetividade espetacularizada, onde o mesmo padrão de comportamentos é identificado.

Trata-se de uma desapropriação da identidade a qual conduz a pessoa a viver inteiramente sobre as influências grupais, abrindo mão de apresentar quem de fato é, assim, a cultura de massas alcança o objetivo de nortear uma identidade alienada, forjada e falseada, de traçar 0 destino de quem permitir ou se enquadrar nos padrões estabelecidos por ela. Esta subjetividade industrializada aparece com o objetivo de preenchimento, um preenchimento que se refere justamente ao vazio existencial que o sujeito abre mão devido a necessidade de segurança e paixão, a paixão de pertencer à massa e identificar-se com ela nos termos proposto pelo espetáculo (16,9).

\subsection{Sublimação: a expressão nos relacionamentos co-dependentes}

Independentemente das variações histórico-culturais e da denominação utilizada, Amélio (apud Sophia) (22) o relacionamento amoroso é uma das áreas fundamentais da nossa vida, sendo de suma importância para o nosso humor, para a nossa capacidade de concentração, para a nossa energia e para a nossa saúde. O momento em que vivemos traz uma extrema fragilidade dos laços humanos, considerada como um amor líquido. Essa forma de relacionar-se transita entre desejos conflitantes de estreitar esses laços e ao mesmo tempo mantê-los frouxos, e nessa tentativa de estreitar seus laços, podemos observar uma espécie de relacionamento codependente. A co-dependência, refere-se, à atitude compulsiva e obsessiva que um indivíduo desenvolve estabelecendo como meta o controle de outras pessoas e relações, como fruto da própria insegurança. Robert Subby especialista em co-dependência a descreve como uma espécie de condição que pode se manifestar psicologicamente, comportamente e emocionalmente devido a exposição do sujeito a um conjunto de regras opressivas por um longo período de tempo. Apesar da co-dependência e do Amor Patológico serem condições díspares, no que se referem à manifestação, elas se assemelham em dois comportamentos: a intromissão na vida do parceiro e a auto responsabilização pela vida dessa outra pessoa ${ }^{(22,23)}$.

Schopenhauer (apud Sophia) destaca que na Idade Moderna, alguns filósofos consideravam o amor como uma patologia, levando esse momento histórico 
a ser conhecido pelo pessimismo romântico. O percussor desse movimento foi Arthur Schopenhauer que acreditava que 0 amor referia-se apenas a um impulso que culmina a reprodução da espécie, sendo este responsável em atrapalhar a vida do sujeito, 0 desorientando. Quando a maneira de amar é patológica e o indivíduo não se mostra apto nem para melhorar sua maneira de amar e nem para romper com o relacionamento insatisfatório, 0 sofrimento passa a ser excessivo e a saúde mental do indivíduo pode estar comprometida.

De acordo com Freud (apud Sophia) (22), o chamado instinto amoroso refere-se a tudo aquilo que pode ser considerado como alvo de amor, por exemplo, a família, filhos, o saber, objetos específicos e a própria humanidade. Desta forma, Freud diz que trata-se de processos mentais que são internos e que acabam por dirigir a libido do sujeito a um outro objeto que ele elenca como objeto de amor tendo como objetivo a obtenção de prazer, de amar e ser amado. Psicologicamente isto pode ser visto como uma espécie de procura narcísica pelo olhar do outro, como uma necessidade de ser aprovado e aceito, estabelecendo uma relação simbiótica, assim como muitos estabelecem simbiose na relação com a mãe.
A escolha amorosa do indivíduo refere-se a uma atualização das relações primárias vivenciadas com as figuras parentais, comumente, o pai e a mãe. Esta procura é uma tentativa do sujeito de reviver novamente $o$ narcisismo infantil para que consiga atingir novamente um sentimento ilusório de onipotência e completude vivenciada na relação com 0 seu cuidador (24).

Ballone (apud Berton) ${ }^{(25)}$ aborda os tipos de amor, que foram postulados por Kant, o qual os categorizou em amor ação, amor afeto e amor paixão. O amor ação trata-se de um estado que busca satisfação própria, e totalmente egoísta, não denota preocupação com o outro, pode ser associado ao que entendemos hoje como amor patológico, percebe-se um desejo de possuir e controlar o outro justamente devido o indivíduo acreditar que somente desta forma, se entrelaçando patologicamente ao outro, irá conseguir alcançar a almejada felicidade. $\mathrm{O}$ amor afeto é saudável e busca o bem estar do ser amado, além do mais, manifesta preocupação genuína pela outra pessoa.

Outro fator que deve ser levado em consideração é que o sujeito que desenvolve um amor patológico pelo outro acaba por repetir comportamentos que outrora foram aprendidos, possivelmente durante sua infância, geralmente essas 
pessoas são indivíduos que não tiveram relacionamentos saudáveis na infância e distante de afetividade no relacionamento com os pais ou até mesmo outros cuidadores, logo, são carentes de afeto e cuidados, e experienciaram momentos de infelicidade durante sua infância, fator o qual propicia a busca desenfreada em encontrar a felicidade de alguma maneira, o indivíduo então acaba por sublimar seu primeiro desejo, a felicidade, em um relacionamento amoroso, o qual por fim, se torna patológico. Desta forma, na busca desenfreada pelo alcance da felicidade 0 indivíduo lança sobre o outro a responsabilidade de fazê-lo propiciar aquilo que somente o indivíduo por si só pode encontrar, sua própria felicidade e maneira de ser feliz, mediante isto, devido sua maneira patológica de lançar tal responsabilidade sobre o outro acaba por estabelecer uma vinculação defeituosa que se origina através da projeção patológica desse indivíduo sobre o outro (25).

\subsection{Sublimação: a expressão na religiosidade}

A experiência do sagrado é universal, na medida em que é um saber do numinoso de ordem psíquica. Com efeito, o primitivo está presente em todo ser humano, e desde sempre. Ao contrário, a chamada "fé" concerne a fatos exteriores à nossa alma, transmitidos por determinada religião particular com seus discursos teológicos, seus dogmas e, sobretudo, seus rituais. Ora, essas diversas religiões, que impõem aquilo em que se deve crer, recalcaram o religioso em geral, comum a toda a humanidade (26).

Desde o advento da modernidade, com a emancipação da razão e o grande apogeu da ciência natural, os cristãos de um modo geral sempre tiveram muita dificuldade e resistência com relação a ciência, isso se deve a todo um processo histórico, desde Aristóteles até Tomás de Aquino ao fazer da ciência uma metafísica religiosa do conhecimento, de modo de tornar inquestionável e indiscutível a ideia sobre Deus, porém, em nosso tempo não há mais espaço para conceitos fechados e dogmáticos, pois no tempo que vivemos tudo é questionável. Aliás, a própria ciência existe para que de fato a verdade possa ser esclarecida, tudo é líquido, até os relacionamentos humanos ${ }^{(27)}$.

Maciel e Rocha ${ }^{(28)}$ destacam que é de suma importância 0 conceito psicanalítico de sublimação quando se intensifica o diálogo da psicanálise com a religião, pois a sublimação tem um papel de grande importância para a compreensão dos processos culturais, e em consequência, para a compreensão do fenômeno religioso. 
Phillippe Julian, em seu livro intitulado "A Psicanálise e o Religioso Freud, Jung, Lacan" (26), se propõe abordar sobre religiosidade e psicanálise utilizando como referencial escritos de grandes psicanalistas existentes na história da psicologia. Em 1904, Freud afirma que a religião é apenas uma projeção de símbolos e configurações psíquicas internas no mundo exterior, desconsiderando a ideia de sobrenatural dizendo que isso não passa de uma criação do próprio ser humano, desta forma, o homem atribui a Deus manifestações as quais lhe são próprias.

Mais tarde com o desenvolvimento de suas pesquisas Freud se propôs a falar sobre a religião em 1907 em seu inscrito intitulado como "Atos obsessivos e práticas religiosas" no qual Freud constatava uma similitude entre os atos do neurótico obsessivo e o cerimonial público da prática religiosa, pois ambos são semelhantes, já que os princípios são os mesmos, trata-se da mesma preocupação fundamental, os mesmos pormenores a serem compridos e exigidos, a mesma sensação de medo e culpa, o que nos faz pensar em um sistema religioso que ao invés de libertar o ser humano, quebrando as cadeias e humanizando 0 homem, deixa-o dependente, alienado e carente de um protetor. Mais tarde, Freud abordará a verdadeira relação entre psicanálise e religião, mostrando como a análise nos faz descobrir a própria razão da crença em Deus. Freud intitulou de Hilflosigkeit uma experiência que ele considera que todo indivíduo passa um dia na vida, que e um estado de desamparo, de ausência de ajuda, de abandono (27).

Desde o nascimento o sujeito vive sob a proteção de outro indivíduo, um bebê quando grita ou chora obtém a atenção da mãe, do pai, ou a pessoa responsável em oferecer esse cuidado intervêm para satisfazer alguma necessidade do bebê, conforme o bebê se desenvolve ela irá aprender a falar e manifestar verbalmente suas necessidades até que surja alguém para atendê-la. Entretanto algum dia vem à ausência de resposta, o responsável por esse cuidado se ausenta, assim, origina-se o primeiro trauma da infância, onde se diminui a proteção direcionada a esse sujeito, o qual se torna vulnerável a experienciar a infelicidade e os riscos.

Mediante isto, com 0 trauma instaurado, o que resta é a saudade do passado em que o pai ou a mãe interferiam, esta saudade, de acordo com Freud, não é uma saudade propriamente da mãe que é o primeiro objeto de amor da criança, mas sim saudade do pai, o objeto de identificação, objeto que a criança 
atribui à onipotência, ou seja, o Pai com letra maiúscula, o Pai divino, o Deus justo e todo-poderoso aparecem-nos como magnas sublimações do pai e da mãe, desta forma Freud reconhece no ser humano aquilo que ele denomina "religiosidade", religiosidade a qual provém primeiro da incapacidade física de ajudar a si mesmo, e, portanto, de uma necessidade de ajuda ${ }^{(26)}$.

Em um de seus trabalhos, o qual Freud intitulou como "O futuro de uma ilusão" (29), Freud tenta explicar a origem da religião, para isto ele utiliza suas descobertas psicanalísticas através de aplicações históricas sociais. Para Sigmund Freud, a religião surge no indivíduo através do desamparo, o qual, inicialmente, é o desamparo enquanto criança.

Sabe-se que ainda criança 0 indivíduo passa pela fase de escolha do objeto, mediante isto deve entender que a libido do sujeito percorrerá em busca das necessidades narcísicas buscando objetos que proporcione satisfação de suas necessidades, a qual na maioria das vezes será a figura da mãe, aquela que cuida e o alimenta e consequentemente será seu primeiro objeto amoroso e também sua proteção contra os perigos do mundo externo, logo após, na função de proteção a mãe é substituída pela figura do pai, reconhecido como mais forte, entretanto, a relação da criança com o pai será ambígua, pois ao mesmo tempo em que o pai será a figura que irá protegê-lo do perigo, este será o pai que causará perigo, devido à disputa com o pai pela mãe, estabelecida inconscientemente pela criança, assim, a criança admira e teme o pai. Mediante isto, Freud vai afirmar que a formação da religião será uma forma de defesa contra o desamparo infantil, que se manifesta mais tarde no adulto no desamparo que este não quer reconhecer. A religião seria a neurose obsessiva das crianças, a qual surgirá a partir do complexo de Édipo, a partir do relacionamento com o pai $(29,30)$.

Logo, tendo em vista que o objetivo final do ser humano é encontrar a plena felicidade e que a religiosidade surge mais tarde a partir do primeiro abandono vivenciado por esse sujeito, o indivíduo poderá, desta forma, recorrer à religião a elegendo como um mecanismo de defesa, visando sublimar seu desejo inicial que era o cuidado e amparo que lhe assegurava a felicidade no outro, devido ao anterior ter sido perdido e recalcado, desta forma, através da sublimação, o indivíduo redirecionará o foco da sua tentativa frustrante de alcance da utópica felicidade plena para a religiosidade, o resultado dessa ação será a transformação do 
sujeito em um indivíduo totalmente alienado e dependente da verdade imposta pelo outro, sendo extirpado de sua capacidade de pensar por si próprio, o próprio sujeito, homem, passa a não ter mais poder sobre sua criatura, perdendo o controle, sendo sequestrado de si mesmo (31).

De acordo com Souza (apud Cardoso) (31), a alienação humana pode ser definida como um processo de projeção, o sujeito cria uma realidade que acaba por se tornar estranha a si próprio, o que pode ser conhecida como hipostatização, a qual define-se pela atribuição de existência concreta e objetiva a uma realidade fictícia, abstrata ou meramente restrita à incorporalidade do ser humano.

\subsection{Sublimação: a expressão nas redes sociais}

Além da propensão ao espetáculo encontra-se também o comunitarismo considerado como uma das manifestações dessa histeria das massas. Ferreira (9) considera que um dos espaços que mais tem se destacado como cenário do espetáculo são as Redes Sociais de Internet, por meio das quais virtualmente as pessoas vivenciam o simulacro. Temos como exemplo os grupos e comunidades virtuais que atualmente tornou-se o centro do espetáculo, redes onde todos os dias milhares de sujeitos se auto-afirmam felizes e donos de uma vida repleta de alegria, o que na verdade acaba por fugir da realidade, e é justamente a internet que propiciou isso, uma espécie de comunitarismo que tem como função a busca do olhar do outro, desta forma, dando a este voz e visibilidade. Desta forma, tais indivíduos não falam mais em si, mas em nome da comunidade da qual participam, uma forma de se sentir pertencente a um grupo, de atrair visibilidade da sociedade para si ${ }^{(16)}$ além de apregoar a necessidade em autenticar uma falsa obtenção de felicidade, se auto afirmando feliz durante todo o tempo através das redes.

O que chama a atenção não é apenas 0 compartilhamento de experiências superficiais através de objetos adquiridos, mas a negociação com a subjetividade, como se esta fosse desprovida de valor (9).

Carreira (apud Ferreira) (9) destaca que o papel da plateia para o sucesso da representação é essencial, pois mediante a função da plateia o sujeito buscará se auto afirmar feliz, buscando através das redes alcançar o ethos desejado, neste sentido, a figura do outro é essencial nesse processo de legitimação pois será o outro que proporcionará essa legitimação da imagem construída nesse contexto em 
que 0 indivíduo existe de maneira colaborativa, mediante isto, neste espaço virtual em que os aplausos da plateia são tão necessários para se sentir alguém, a ator segue seu percurso teatral correndo atrás daquilo que vem por si só, a felicidade.

De acordo com Kehl (21):

O que se produz é uma versão do "inconsciente coletivo" em escala industrial, com 0 consequente "apagamento" dos sujeitos do inconsciente. Isso é: o inconsciente se manifesta como instância supra imaginária, que não diz respeito aos homens, mas se apresenta a eles como alheio à subjetividade, como resposta positiva ao enigma do desejo do Outro. O desejo do Outro, ao qual o sujeito do inconsciente tenta responder com suas produções sintomáticas e/ou simbólicas, se revela aos homens na universalidade do espetáculo, tornando as produções singulares obsoletas, dispensáveis. Este é um aperfeiçoamento da alienação e do desamparo - portanto, da produção subjetiva de submissão.

\section{CONSIDERAÇÕES}

Através deste estudo, podemos apontar que todo indivíduo carrega em si o desejo de alcançar a plena felicidade. Entretanto, sabe-se que a civilização e a cultura são um dos grandes impasses que dificultam o alcance da utópica felicidade, além do mais, encontra-se o princípio de realidade que faz o princípio de prazer reduzir suas expectativas e converte-se a ele, o qual impõe uma série de limites ao projeto de vida feliz do indivíduo.

Prado e Gomes (32) observam que torna-se ambígua a atuação na vida do ser humano, ainda que tenha como objetivo proteger o indivíduo de situações que o leve ao sofrimento, esta acaba por provoca-lo, o que acaba levando o indivíduo desenvolver sentimentos negativos contra a própria sociedade que está inserido. São as próprias restrições que a vida civilizada impõe que acaba por produzir os sofrimento, surgindo, desta forma, as neuroses justamente devido a incapacidade do homem de suportar 0 sofrimento que surge por meio do processo civilizatório como destaca Sigmund Freud.

No trabalho de Freud intitulado como "O mal-estar na civilização", o autor faz significativas considerações sobre a busca da tão sonhada e utópica felicidade pelo ser humano e sobre as fontes do sofrimento que atinge o ser humano. Diante disto, Freud percebe que a felicidade é o propósito da vida de todo sujeito, a qual pode tomar dois caminhos, o de evitação de tudo que provoque desprazer e dor e o da vivência real dos prazeres, o qual é considerado o caminho da felicidade verdadeira ${ }^{(32)}$.

Entretanto, como indivíduos pertencentes a uma sociedade que nos 
impõe cobranças o tempo todo, somos reprimidos em nossos mais íngremes desejos, desta forma, resta ao ser humano recorrer ao mecanismo de sublimação, sendo obrigados a desviar sua libido, desejos e prazeres a objetos mais socialmente aceitos de acordo com os critérios de aceitação da civilização.

Devido à necessidade do indivíduo de se auto afirmar feliz por conta de tais imposições sociais que são introjetadas como critério para serem aceitos socialmente, origina-se a teatralidade, onde o sujeito passa a pertencer à sociedade do espetáculo, preso a sua necessidade de alcançar a utópica felicidade. Mediante isto, ocorre o sequestro da individualidade $e$ subjetividade desse indivíduo, originando a subjetividade industrializada, a qual desencadeará a histeria das massas que provoca a perca da noção de autenticidade, e o único objetivo do sujeito passa a ser o de afirmar uma falsa felicidade a qual é vista como necessária para a satisfação egóica do próprio indivíduo, fazendo-o acreditar e considerar como verdade o seu próprio engano. A partir disto, chega-se a conclusão de que vários são os caminhos de uma vida feliz, mas por nenhum deles se conseguirá alcançar tudo que desejamos, cabe ao próprio individuo subjetivado e único, encontrar, identificar e aceitar sua maneira particular de ser e se fazer feliz.

\section{REFERÊNCIAS}

1. Inada JF. Felicidade e Mal-Estar na Civilização. Rev AdVerbum 2011; 6(1): 7488. [citado em 01 de outubro de 2017]. Disponível em: https://www.psicanaliseefilosofia.com.br/ad verbum/vol6_1/06_01_06felicidademalesta rciviliz.pdf.

\section{Zimerman DE. Fundamentos}

Psicanalíticos: Teoria, Técnica, Clínica Uma Abordagem Didática. Porto Alegre (RS): Artmed; 2009. [citado em 01 de outubro de 2017]. Disponível em: https://books.google.com.br/books?hl=pt$B R \& \mid r=\& i d=c 1 R 7 x \_Z$ Z $s c C \& o i=f n d \& p g=P A$ $6 \& \mathrm{dq}=$ Fundamentos+Psicanal\%C3\%ADtic os:+Teoria,+T\%C3\%A9cnica,+Cl\%C3\%AD nica+\%E2\%80\%93+Uma+Abordagem+Did
\%C3\%A1tica\&ots=IYsi9Bd1wv\&sig=RoRq F9RX1QVOjH7e2|4a_ejMxIs\#v=onepage\& $\mathrm{q}=$ Fundamentos $\% 20$ Psicanal\%C3\%ADtico s\%3A\%20Teoria\%2C\%20T\%C3\%A9cnica \%2C\%20Cl\%C3\%ADnica\%20\%E2\%80\%9 3\%20Uma\%20Abordagem\%20Did\%C3\%A 1 tica\& $f=$ false

3. Santiago J. Freud e sua Política da Felicidade. Rev Estudos Lacanianos 2008; 1(2): 1-14. [citado em 01 de outubro de 2017]. Disponível em: http://pepsic.bvsalud.org/pdf/rel/v1n2/v1n2 a07.pdf.

4. Graziano LD. A Felicidade Revisitada: Um estudo sobre bem-estar subjetivo na visão da Psicologia Positiva. São Paulo. Tese [Doutorado em Psicologia em Escolar e do Desenvolvimento Humano] Universidade de São Paulo; 2005. [citado 
em 20 de agosto de 2017]. Disponível em: http://www.teses.usp.br/teses/disponiveis/4 7/47131/tde-23052006-164724/en.php.

5. Sponville AC. A Felicidade, Desesperadamente. $4^{\underline{a}}$ ed. São Paulo (SP): Martins Fontes; 2010. [citado em 20 de agosto de 2017]. Disponível em: http://abdet.com.br/site/wp-

content/uploads/2014/10/A-Felicidade-

Desesperadamente.pdf

6. Saroldi N. O Mal-Estar na Civilização: As Obrigações do Desejo na era da Globalização. 1a ed. Rio de Janeiro (RJ): Civilização Brasileira; 2012.

7. Llosa MV. A Civilização do Espetáculo: Uma Radiografia do Nosso Tempo e da Nossa Cultura. Rio de Janeiro: Objetiva; 2013.

8. Sebold RL. Reflexões Sobre a Felicidade e Sofrimento: Alguns Litorais. [Trabalho de Conclusão de Curso]. Porto Alegre (RS): Universidade Federal do Rio Grande do Sul - UFRGS; 2013. [citado em 20 de agosto de 2017]. Disponível em: https://www.lume.ufrgs.br/bitstream/handle /10183/95476/000913996.pdf?sequence=1

9. Ferreira LVG. O Espetáculo do Simulacro na Cultura Contemporânea. [Trabalho de Conclusão de Curso]. Ariquemes (RO): Faculdade de Educação e Meio Ambiente - FAEMA; 2015.

10. Frederico C. Debord: Do Espetáculo ao Simulacro. Rev Matrizes 2010; 4(1): 179-191. [citado em 20 de agosto de 2017]. Disponível em: http://www.redalyc.org/pdf/1430/14301676 4011.pdf.

11. Ferraz RB, Tavares H, Zilberman ML. Felicidade: Uma Revisão. Rev de Psiquiatria Clínica 2007; 34(5): 234-242. [citado em 20 de agosto de 2017]. Disponível em: http://www.scielo.br/pdf/rpc/v34n5/a05v34n 5.
12. Fontenelle IA. O Trabalho da llusão: Produção, Consumo e Subjetividade na Sociedade Contemporânea. Rev Interações 2005; 10(19): 63-86.

13. Silva EBT. "Mecanismos de Defesa do Ego." [Trabalho de Curso]. Rev Psicologia.PT 2011; 3: 1-5. [citado em 20 de agosto de 2017]. Disponível em: http://www.psicologia.pt/artigos/textos/TLO 212.pdf

14. Almeida CAM. A Histeria e Suas Formas de Apresentação na Contemporaneidade. ljuí. Monografia [Graduação em Psicologia] - Universidade Regional do Noroeste do Estado do Rio Grande do Sul; 2016. [citado em 01 de outubro de 2017]. Disponível em: http://bibliodigital.unijui.edu.br:8080/xmlui/b itstream/handle/123456789/3312/Cesar\%2 OAgostinho\%20Muller\%20de\%20Almeida. pdf?sequence $=1$

15. Ávila LA, Terra JR. Histeria e Somatização: O Que Mudou. Rev Jornal Brasileiro de Psiquiatria 2010; 59(4): 333340. [citado em 01 de outubro de 2017]. Disponível em: https://www.researchgate.net/profile/Lazslo Avila2/publication/262516260_Hysteria_a nd_somatization_What_has_changed/links /53f607970cf22bē01c400097//Hysteriaand-somatization-What-has-changed.pdf

16. Costa DS, Lang CE. Histeria Ainda Hoje, Por Quê?. Rev Psicologia USP 2016; 27(1): 115-124. [citado em 01 de outubro de 2017]. Disponível em: http://www.redalyc.org/pdf/3051/30514537 6015.pdf.

17. Rocha AR. Desejo e Insatisfação: A Histeria da Contemporaneidade. Campina Grande. Monografia [Graduação em Psicologia] - Universidade Estadual da Paraíba Campus I; 2013. [citado em 01 de outubro de 2017]. Disponível em: http://dspace.bc.uepb.edu.br/jspui/bitstrea $\mathrm{m} / 123456789 / 2354 / 1 / P D F \% 20-$

\%20Amanda\%20Ramalho\%20Rocha.pdf. 


\section{AMERICAN}

PSYCHIATRIC ASSOCIATION et al. DSM-IV: Manual de Diagnóstico e Estatística das Perturbações Mentais. 4를 ed. Washington, 1994.

19. Kellener D. A cultura da mídia e o triunfo do espetáculo. Rev Líbero 2007; 6(11).

20. Pacheco CA. O Complexo de Édipo e sua Importância no Diagnóstico e Tratamento. Rio de Janeiro. Dissertação [Mestrado em Psicanálise, Saúde e Sociedade] - Universidade Veiga de Almeida; 2009. [citado em 20 de agosto de 2017]. Disponível em: http://livros01.livrosgratis.com.br/cp116153 .pdf.

21. Kehl MR. O Espetáculo como Meio de Subjetivação. Rev Concinnitas 2015; 1(26): 71-85. [citado em 01 de outubro de 2017]. Disponível em: http://www.epublicacoes.uerj.br/index.php/concinnitas/a rticle/viewFile/20102/14422.

22. Sophia EC. Amor Patológico: Aspectos Clínicos e de Personalidade. São Paulo. Dissertação [Mestrado em Ciências] Universidade de São Paulo; 2008. [citado em 20 de agosto de 2017]. Disponível em: http://www.psiquiatriafmusp.org.br/pg/userf iles/Dissertacoes\%20e\%20Teses/2008/Dis serta\%C3\%A7\%C3\%A30\%20aspectos\%2 0cl\%C3\%ADn\%20e\%20de\%20person.pdf.

23. Carvalho LS, Negreiros F. A CoDependência na Perspectiva de Quem Sofre. Rev Boletim de Psicologia 2011; 61(135): 139-148. [citado em 01 de outubro de 2017]. Disponível em: http://pepsic.bvsalud.org/pdf/bolpsi/v61n13 5/v61n135a02.pdf.

24. Sandiães CFS. A escolha do objeto de amor na patologia narcísica. Portugal. Dissertação [Mestrado em Psicologia Clínica] - ISPA - Instituto Universitário; 2013. [citado em 20 de agosto de 2017]. Disponível em: http://repositorio.ispa.pt/bitstream/10400.1 2/2792/1/18122.pdf.
25. Berton ALM, Volpi JH. Amor e Oralidade: Uma Reflexão sobre o Amor Patológico. In: Anais do XX Congresso Brasileiro De Psicoterapias Corporais; 2015; Curitiba (PR), Brasil. Curitib: Centro Reichiano; 2015. p. 1-16. [citado em 20 de agosto de 2017]. Disponível em: http://www.centroreichiano.com.br/artigos/ Anais_2015/BERTON_Ana_Lorena_Amor e_oralidade.pdf.

26. Julien P. A Psicanálise e o Religioso: Freud, Jung, Lacan. $1^{\text {a }}$ ed. Rio de Janeiro (RJ): Zahar; 2010.

27. Santos RF. Freud e a Religião: Desconforto e a Busca da Fé. Rev Brasileira de Estudos Intelectuais 2010; (13): 1-100. [citado em 20 de agosto de 2017]. Disponível em: http://www.etnia.org.br/ethnic/revista1307J 10/files/revista\%2013.pdf\#page=91.

28. Maciel KDSA, Rocha ZJB. Freud e a Religião: Possibilidades de Novas Leituras e Construções Teóricas. Psicologia: Ciência e Profissão 2008; 28(4): 742-753. [citado em 20 de agosto de 2017]. Disponível em: http://www.scielo.br/pdf/pcp/v28n4/v28n4a 07.

29. Freud $S$, et al. O Futuro de Uma Ilusão. Rio de Janeiro (RJ): Imago; 1997.

30. Passos MC, Polak PM. A Identificação como Dispositivo da Constituição do Sujeito na Família. Rev Mental 2004; 2(3): 39-50. [citado em 01 de outubro de 2017]. Disponível em: http://pepsic.bvsalud.org/pdf/mental/v2n3/v 2n3a04.pdf.

31. Cardoso MR. O Sequestro na Religião: Porque o Mundo Precisa de um Deus?. Rev Húmus 2011; 1(3): 56-75. [citado em 01 de outubro de 2017]. Disponível em: http://www.periodicoseletronicos.ufma.br/in dex.php/revistahumus/article/view/1620/12 85.

32. Prado AC, Gomes AP. Felicidade e Sofrimento: Aproximações entre Freud e 
Schopenhauer. Rev Sapere Aude 2014; 5(10): 160-167. [citado em 01 de outubro de 2017]. Disponível em:
http://200.229.32.55/index.php/SapereAud e/article/view/8710/pdf

\section{Como citar (Vancouver)}

Rocha VHC, Bergamini GB, Samuelsson E, Joner C, Schneider LF. A utopia da plena felicidade e a expressão da histeria das massas na contemporaneidade. Rev Cient Fac Educ e Meio Ambiente [Internet]. 2018;9(1):442464. DOI: http://dx.doi.org/10.31072/rcf.v9i1.558 